\title{
Jogos teatrais como instrumentos pedagógicos e transformadores de realidades sociais
}

\author{
Rita de Cássia Vieira ${ }^{1}$ \\ Universidade Federal de Minas Gerais, Belo Horizonte-MG, Brasil
}

Neves, L. R., \& Santiago, A. L. B. (2009) O uso dos jogos teatrais na educação: Possibilidades diante do fracasso escolar. Campinas, SP: Papirus.

Até ser reconhecido tal qual nos dias de hoje, o teatro vem, ao longo dos tempos, sofrendo transformações determinadas pelas necessidades vividas pelos seres humanos. Sua história se confunde com a história da humanidade: lugar dos ritos nas sociedades mais primitivas, espaço de representação de lendas relacionadas a deuses e heróis, tragédias, comédias, mortes e renascimentos contam a história dessa forma de expressão artística tão antiga como a própria humanidade (Berthold, 2005). Nessa mesma perspectiva, pode-se afirmar também que não é recente a utilização dos jogos teatrais com fins educativos, que já tiveram a sua contribuição nos processos de ensino e aprendizagem reconhecida por grandes educadores, a exemplo de Comenius e Pestalozzi. No mundo ocidental, os primeiros registros do uso dessa arte numa perspectiva pedagógica remontam à civilização grega, sendo que Platão e Aristóteles o consideraram fundamental na educação.

$\mathrm{Na}$ atualidade, muitos autores e educadores reafirmam e comprovam em suas ações a relevância do teatro como coadjuvante nos processos de aprendizagem e desenvolvimento humanos. Concebido como uma produção cultural e histórica tipicamente humana, o teatro é visto como uma prática passível de, a partir da imaginação dramática, capacitar a pessoa a estabelecer relações entre as idéias e sua interação, se reconhecer na obra, e sintetizar todo esse processo na busca de compreensão e apreensão de seu mundo. Thomaz (2007) narra uma experiência onde práticas com jogos teatrais possibilitaram a educandos se localizarem como seres biopsicossociais e, a partir desse posicionamento enquanto seres de cultura, desenvolver-se na sua relação com o mundo. Reafirma-se nesse trabalho a participação dessa arte plural no desenvolvimento individual e coletivo: ao mesmo tempo em que é capaz de atuar no espaço da subjetividade ampliando as fronteiras entre o pensar, o sentir e o agir, o

\footnotetext{
${ }^{1}$ Endereço para correspondência:

Rita de Cássia Vieira. Universidade Federal de Minas Gerais. Faculdade de Educação, Departamento de Ciências Aplicadas a Educação. Avenida Antonio Carlos, 6627. Pampulha. CEP.31.270-900. Belo HorizonteMG, Brasil.
}

teatro oferece possibilidades de ampliar também, no nível de uma coletividade, o espaço em que a educação ocorre. E é aí nesse âmbito que ele pode verdadeiramente se afirmar, pois, "nesse sentido, a educação ultrapassaria o processo de formação do indivíduo, alcançando o patamar de toda a humanidade" (Thomaz, 2007, p. 14).

É nessa perspectiva que a presente obra foi elaborada pelas autoras, ambas educadoras e pesquisadoras com significativa atuação nos campos da psicologia e da psicanálise. A proposta central do livro é discutir a utilização dos jogos teatrais como instrumentos pedagógicos e transformadores de realidades sociais. Apostando na possibilidade destes em favorecer a aprendizagem e o desenvolvimento de crianças e jovens em situação de fracasso escolar, a publicação reflete especialmente a partir da relação entre o teatro, a psicologia, a psicanálise e a educação.

Com base nessa proposta, o livro compõe-se de três capítulos, nomeados de acordo com referências a textos e/ou grupos teatrais. O primeiro deles se intitula "Ponto de Partida": o uso do teatro na Educação e apresenta a trajetória histórica da vinculação entre teatro e educação no Ocidente. Seguindo um percurso paralelo, os jogos estariam ao lado dos seres humanos desde os primórdios do desenvolvimento, misturando-se num espaço onde o lúdico se confundiria com a regra, significando a gênese da atividade teatral. Concordando com pesquisadores da história do teatro que consideram a civilização grega como o marco do teatro ocidental, as autoras fazem questão de demarcar que este, "como rito ou representação, é tão velho como a humanidade" (p. 15). É, portanto, a civilização grega que, com sua educação direcionada a toda a pólis, vai disseminar, por meio da tragédia e da comédia, uma idéia de auto-educação partilhada pelos membros da comunidade. A civilização romana também viu propósitos educacionais nessa arte e na Idade Média o teatro continua na sua trajetória para se estabelecer como uma via de acesso à cultura e à educação de um povo, na sua maioria, iletrado. Sem deixar de observar o uso do teatro como instrumento de poder e massificação, o texto segue marcando o seu florescimento nas instituições escolares renascentistas 
e destacando o papel de relevância desempenhado pelo filósofo iluminista Jean-Jacques Rousseau. Este, ao propor uma nova concepção de criança para a educação, aponta, consequentemente, para novos direcionamentos na forma de se educar. $\mathrm{O}$ texto não deixa dúvidas quanto à contribuição indireta de Rousseau, que, embora não tenha teorizado especificamente sobre o emprego do teatro nos processos educativos, influenciou sobremaneira com suas idéias as reflexões de vários estudiosos modernos no campo da educação e da psicologia e "sua concepção do uso do jogo nesses processos pode ter contribuído para a construção do que conhecemos hoje como jogos teatrais" (p. 22). O capítulo finaliza mostrando de forma breve as perspectivas para as artes em geral no âmbito da educação - incluindo aí o teatro, claro - e, partindo também de um olhar histórico que se inicia com as ações educativas implementadas pelos jesuítas e chega até a atualidade, apresenta o cenário que vem sendo instituído entre educação e teatro no Brasil.

"Vamos brincar de brincar": o uso dos jogos na educação é como se intitula o segundo capítulo, que tem por objetivo apresentar a trajetória do uso dos jogos e dos jogos teatrais na educação. A construção do texto segue direcionamento semelhante ao apresentado no capítulo anterior e privilegia o viés histórico. O capítulo inicia fazendo uma análise da noção de jogo sob esse ponto de vista e mostra como foi necessária uma verdadeira revolução no pensamento educacional - preparada por Rousseau e levada a termo pelo Romantismo - para que a idéia de jogo como valor educativo pudesse enfim ser enunciada por pensadores, filósofos e educadores, verdadeiros precursores que ainda hoje se constituem em referência no estudo do entrelaçamento entre teatro e educação. No subtítulo Os jogos na Psicologia, o tema é tratado, inicialmente, a partir das proposições apresentadas por Piaget e Vigotski, para quem os jogos têm um significativo papel no desenvolvimento cognitivo da criança. Na sequência, as autoras incluem o campo da Psicanálise e apresentam as contribuições de Freud, Melanie Klein, Anna Freud, Winnicot e Lacan no que se refere aos jogos infantis. O texto esclarece, contudo, que tais contribuições estão localizadas mais no âmbito clínico, curativo, e menos no contexto educativo, onde esses autores não optaram por focalizar seus estudos. A contribuição da psicologia é encerrada com a apresentação do trabalho de Jacob Levi Moreno e suas técnicas do psicodrama e sociodrama, amplamente utilizadas com propósitos terapêuticos e educativos. Prosseguindo na exploração da noção de jogo teatral, esse capítulo finaliza fazendo uma apresentação de quatro autores com reconhecida produção no campo da arte-educação - Viola Spolin, Augusto Boal, Olga Reverbel e Joana Lopes - e que sugerem a utilização desse tipo de jogo como instrumento capaz de favorecer um incremento nas capacidades cognitivas dos alunos.

O terceiro e último capítulo é denominado "Seis personagens à procura de um autor": o uso dos jogos teatrais em uma perspectiva pedagógica e subjetiva. Descreve uma experiência de utilização dos jogos teatrais como prática pedagógica e terapêutica, desenvolvida por uma das autoras junto a um grupo de crianças em situação de fracasso escolar. Das seis crianças que participaram da proposta, todas cursando o ensino fundamental em escolas da rede pública de Belo Horizonte, foi escolhido um caso para apresentar com detalhes os passos metodológicos desenvolvidos, bem como para realizar uma análise das repercussões do trabalho na criança. A partir dos resultados obtidos, as autoras concluem que, confirmando hipóteses iniciais, os jogos teatrais se constituem em instrumentos passíveis de utilização com propósitos pedagógicos e, além disso, são agentes capazes de atingir a dimensão subjetiva. Ao trabalhar "na hiância entre o saber pedagógico e o saber psicológico" (p. 117), nessa lacuna onde muitas vezes esses saberes "falham ao tentar anular a expressão da dificuldade enquanto efeito da linguagem" (Santiago, 2005, p. 26), eles se apresentaram como uma ferramenta possível na reversão de quadros de fracasso escolar.

Essas e outras observações integram "Um baú de fundo fundo", um pequeno capítulo com considerações finais. Em síntese, a leitura do livro, ao apresentar a potencialidade do teatro em se constituir numa prática transformadora, deixa no ar uma sensação de querer saber mais sobre o assunto. A divulgação, em detalhes, de uma experiência do uso pedagógico/terapêutico dos jogos teatrais - avaliada como bem sucedida pelas autoras - concede materialidade e visibilidade à proposta central da obra, acrescentando também atualidade a um debate que não é novo. Além do mais, apesar da discussão acerca da relação entre teatro e educação ser antiga, o texto, por suas características próprias, apresenta-se como uma obra original e um acréscimo a um tipo de literatura ainda escassa na atualidade. Por esses motivos, pode-se afirmar que a obra apresenta elementos que, sem dúvida, concorrerão para transformá-la num título de referência sobre o assunto, um texto útil para educadores em geral e estudiosos do tema.

\section{Referências}

Berthold, M. (2005). História mundial do teatro. São Paulo: Perspectiva.

Thomaz, S. B. (2009). Teatro na escola: cultura $e$ imagens do corpo no processo educativo. Recuperado em 03 setembro 2009, de http://www.anped.org.br/ reunioes/30ra/grupo.../GE01-3656

Santiago, A. L. B. (2005). A inibição intelectual na psicanálise. Rio de Janeiro: Jorge Zahar.

Rita de Cássia Vieira é Doutora em Educação pela Faculdade de Educação da Universidade Federal de Minas Gerais. Psicóloga e pesquisadora do Laboratório de Psicologia e Educação Helena Antipoff (LAPED)/FaE/UFMG.

Recebido: 23/05/2010

$1^{a}$ Revisão: $28 / 06 / 2010$

Aceite final: 14/07/2009 